\title{
Historical Reasoning: Towards a Framework for Analyzing Students' Reasoning about the Past
}

\author{
Jannet van Drie • Carla van Boxtel
}

Published online: 3 October 2007

(C) Springer Science + Business Media, LLC 2007

\begin{abstract}
This article explores historical reasoning, an important activity in history learning. Based upon an extensive review of empirical literature on students' thinking and reasoning about history, a theoretical framework of historical reasoning is proposed. The framework consists of six components: asking historical questions, using sources, contextualization, argumentation, using substantive concepts, and using meta-concepts. Each component is discussed and illustrated by examples from our own research. The article concludes with suggestions on how to use the framework both in future research and in educational practice.
\end{abstract}

Keywords Historical reasoning · Domain-specific reasoning · History learning · Interaction analysis

Traditionally, the focus of history education has been on the content, and learning history mainly implied memorizing important facts and data from the (national) past. Recent views of learning history have emphasized learning to reason with facts and stories about the past, and learning to create new coherent stories (McCarthy Young and Leinhardt 1998a; O'Reilly 1991; Perfetti et al. 1995). Reasoning with information about the past can be considered as an important cultural practice of societies. It has been incorporated into the history curriculum in several countries and is considered to empower students to understand history, as well as social life in general. For instance, the ability to argue about historical artefacts, rather than accept or reject uncritically what is presented, is viewed as a significant capacity for participation in a democratic society (Rosa et al. 1998; Kuhn et al. 1994). In line with this, Barton and Levstik (2004) argue that history should promote reasoned judgment about important human matters. This requires the ability to appreciate the context, to deliberate and judge, to reflect on the causes of historical events and

J. van Drie $(\triangle) \cdot C$. van Boxtel

Graduate School of Teaching and Learning, Universiteit van Amsterdam, Spinozastraat 55,

1018 HJ, Amsterdam, The Netherlands

e-mail: j.p.vandrie@uva.nl

C. van Boxtel

e-mail: c.a.m.vanboxtel@uva.nl 
processes, their relative significance, and the potential outcomes of alternative courses of action, and, lastly, to reflect on the impact of the past on the present.

Educational research has shown increased interest in history learning since the 1990s (e.g., Carretero and Voss 1994; Leinhardt et al. 1994; Voss 1997; Voss and Carretero 1998; Wilson 2001). These studies have been conducted from a predominantly cognitive perspective on learning and include expert-novice comparisons, reasoning with historical documents and historical explanations, and the teaching of history. This line of research has recently been broadened with studies from a socio-cultural perspective (e.g., Barton 2001; Barton and Levstik 2004; Wertsch and Rozin 1998).

Although it is by now generally agreed that learning history implies more than learning facts about the past, different terms are used to describe the aim of history education, for instance, historical literacy (e.g., Lee 2004, 2007; Perfetti et al. 1995; Roderigo 1994), historical thinking (e.g., Husbands 1996; Schreiber et al. 2006; Seixas 1993, Spoehr and Spoehr 1994; VanSledright and Frankes 2000; Wineburg 2001), historical consciousness (e.g., Goegebeur et al. 1999; Jeismann 1997; Von Borries 1997), and historical reasoning (e.g., Kuhn et al. 1994; Leinhardt et al. 1994). Some authors relate historical thinking and reasoning to historical consciousness or literacy. Perfetti et al. (1995), for example, state that historical literacy involves learning historical events (a story) combined with the use of articulate reasoning.

In our research work we have adopted the term historical reasoning, approaching the construct from an educational perspective. Whereas the terms historical literacy and historical consciousness refer to more general abilities and attitudes, the term historical reasoning emphasizes the activity of students and the fact that when learning history, students not only acquire knowledge of the past, but also use this knowledge for interpreting phenomena from the past and the present. This emphasis on activity and knowledge use is in line with socio-constructivist and socio-cultural theories of learning, which argue that knowledge is actively constructed (Brown et al. 1989; Duffy and Jonassen 1992) and mediated by the use of language and tools (Wertsch 1991), rather than transmitted or passively received. By referring to verbally explicated reasoning, in speech or in writing, the term historical reasoning puts more emphasis on the active role of students than other terms have done so far.

Although the term historical reasoning is often used, it is much less defined or described in detail. Leinhardt et al. (1994) studying historical reasoning from the perspective of instructional explanations given to students, described it as "the process by which central facts (about events and structures) and concepts (themes) are arranged to build an interpretative historical case" (p. 134), which then requires analysis, synthesis, hypothesis generation, and interpretation. Most studies related to historical reasoning focus on only one specific aspect, such as the use of evidence (e.g., Rouet et al. 1996; Wineburg 1991a), or the explanation of historical events (e.g., Carretero et al. 1997). While these studies provide many important insights into these specific aspects, historical reasoning as such can be seen to involve a whole range of more or less interrelated activities. For instance, the writing of an essay on a historical topic involves several activities such as contextualizing the topic in a broader historical context, providing explanations for events, describing changes, and comparing historical sources. Such a more inclusive view of the activities that makes up the process of historical reasoning is lacking in most of the research work (cf. Seixas 1993).

In this article we propose a theoretical framework for historical reasoning, which can be used to describe and study historical reasoning in secondary education in terms of its' constituting activities. We will discuss the different components of the framework by referring to the findings of empirical studies and by providing examples from our own 
research. We conclude the article with suggestions on how to use the framework both in future research and in educational practice.

\section{A Framework for Historical Reasoning}

In our studies on history learning in secondary education, we needed a framework that would enable us to analyze students' reasoning both in writing and speaking, for example, in collaborative learning situations. We wanted to create a framework that would allow us to describe progression in both reasoning and learning in history, as well as to identify the effects of different learning tasks and learning tools. From the available research literature, we identified components of historical reasoning so that to use them as a starting-point for the analysis of our data. We subsequently refined and extended our initial set of components through analyzing the quality of historical reasoning in student essays, chat discussions in an electronic learning environment, small group discussions, and whole-class discussions. Using the revised components as a ground for our coding schemes, we were able to identify differences in the amount and quality of historical reasoning between different tasks, as well as between experts and novices within the domain of history in various studies. For example, we found that as a starting point for historical inquiry by students, an evaluative question appeared to be more powerful than an explanatory question to provoke historical reasoning (Van Drie et al. 2006). In a study investigating the effects of different representational tools, as, for instance, an argumentative diagram and a matrix, we were able to show through the analysis of chat discussions and students essays that the amount and type of historical reasoning was shaped by the format of the representation (Van Drie et al. 2005). In a study in which we focussed on historical reasoning and its' mediation through pictures and task instructions, we compared student dyads with wholeclass discussions (Van Boxtel and Van Drie 2003). Our analysis showed teacher-guided class discussions to exhibit more contextualization, more explanatory questions, as well as more use of abstract historical concepts as compared to discussions in student pairs. In an expert-novice study, we were able to use the framework to bring to light differences in historical reasoning between novices of different ages, as well as between novices and experts (Van Boxtel and Van Drie, 2004).

Figure 1 presents in a schematic form the framework of historical reasoning we developed. The framework comprises six components: (a) asking historical questions, (b) using sources, (c) contextualization, (d) argumentation, (e) using substantive concepts, and (f) using meta-concepts. We define historical reasoning in the context of history education as an activity in which a person organizes information about the past in order to describe, compare, and/or explain historical phenomena. In doing this, he or she asks historical questions, contextualizes, makes use of substantive and meta-concepts of history, and supports proposed claims with arguments based on evidence from sources that give information about the past. The quality of students' historical reasoning is influenced by the nature of the task, the topic or theme, as well as the historical materials provided. Furthermore, it is shaped by the historical knowledge, the historical thinking strategies (here we mean heuristics that support higher-order operations such as writing an essay on a historical topic or interpreting a historical cartoon), and by the epistemological beliefs the student brings to the task (Lee and Ashby 2000; Maggioni et al. 2004; Wineburg 1991a, b, 1998). We agree with Booth (1994) that only within the dimensions of the nature of the task, the topic or theme, the historical materials, and the background knowledge one is expected to bring to the task, that any meaningful statement can be made about the level of 


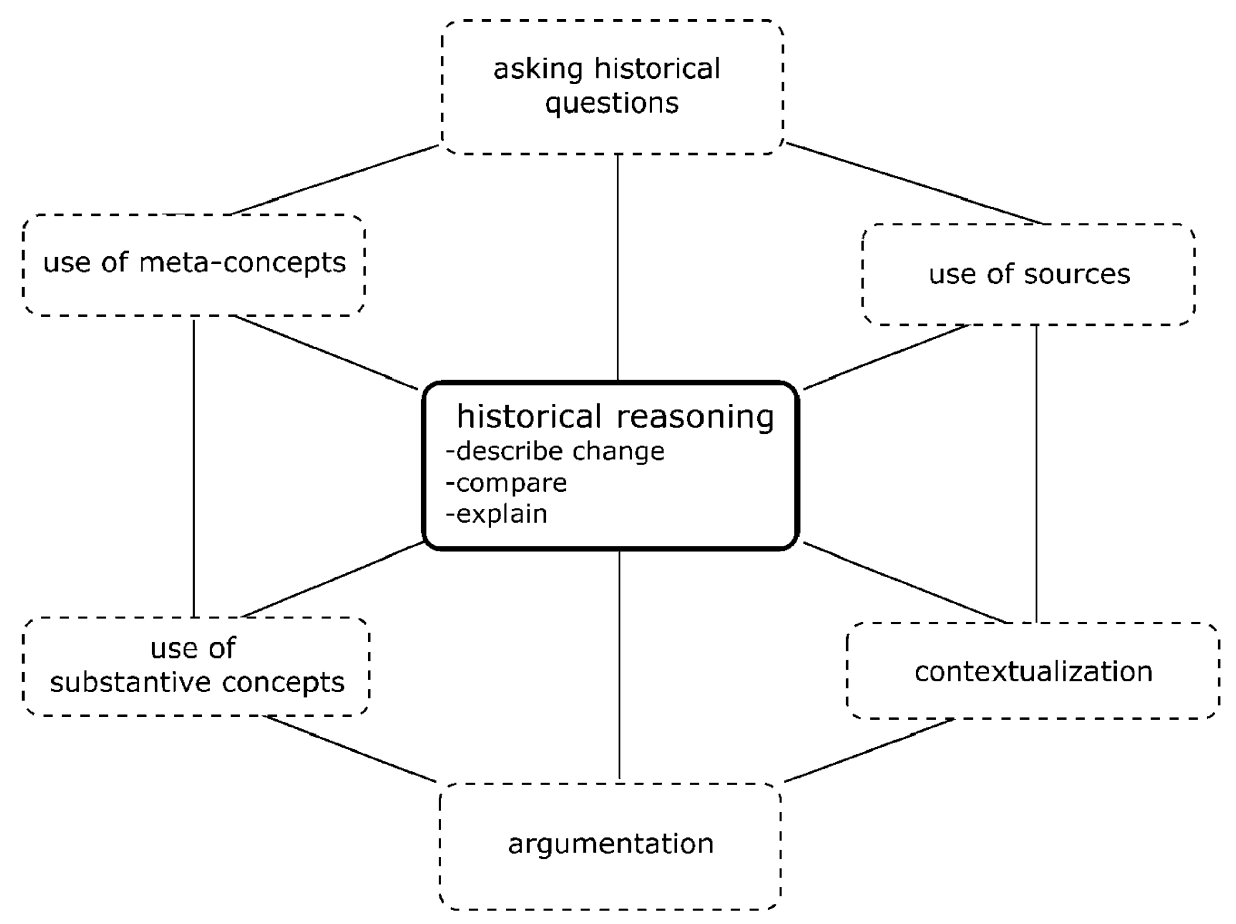

Fig. 1 Components of historical reasoning

historical reasoning displayed. Hence, because the level of historical reasoning is always relative, we do not define fixed categories of high and low level historical reasoning within the framework.

We consider the components identified in the framework first and foremost as analytical tools for describing the activity of historical reasoning. While the framework identifies analytically separable components, these do not refer to entities that occur clearly separated in reality, which is indicated by the lines between the six components. Explaining a historical event, for example, implies contextualization, argumentation based on historical sources, and the use of both substantive concepts and meta-concepts, such as cause and effect. Both, meta-concepts and substantive concepts related to the discipline of history, shape historical questions, contextualization, use of sources, and argumentation. The relative importance of each of these components in historical reasoning will depend on the complexity and the level of the historical problem or question one wants to address, the information and means available, the product that is asked for, and the person's knowledge and experience (see also Van Drie et al. 2006).

In the following sections we describe each component of historical reasoning separately, presenting important findings of empirical studies related to these components and providing examples from our own studies to further illustrate each component and its' possible occurrence in research data and classroom reality.

Asking historical questions

A line of reasoning is always constructed during the encounter with a problem or a question. Schreiber et al. (2006) describe the willingness and ability to ask, recognize, and 
understand historical questions as one of the competencies underlying historical thinking. Questioning in educational research has been approached mainly as a reading strategy to improve understanding of texts and much less as a means for domain specific reasoning. Questioning may function as an "engine" for historical reasoning. A line of reasoning is not only constructed in relation to an initial question, each component of historical reasoning can be shaped by its own types of questions.

In history, different types of questions are used, such as descriptive questions, causal questions, comparison questions, and evaluative questions. These questions can be asked in relation to historical phenomena (e.g., "What caused World War I?"), but also in relation to the sources that give information about the past (e.g., "Does this document provide enough evidence?"). Evaluative questions are variations of descriptive, causal, or comparison questions. The explanatory question "What caused World War I?" becomes an evaluative question when it is reformulated as "What is the most important cause for the outbreak of World War I?" An example of an evaluative question in relation to historical changes is "Where the changes in the sixties in the Netherlands revolutionary or not?" Historical questions are often shaped by meta-concepts, as, for instance, causation, change, and continuity (Counsell 2000). Not all questions ask for the transformation of knowledge and information. For example, the question "When is the beginning of the Middle Ages?" does not require historical reasoning for a student who has learned that the Middle Ages begin in $500 \mathrm{AC}$ and is supposed to give this date. However, depending on prior knowledge, available information, and the context of the question at hand, sometimes factual questions do ask for reasoning. The same question "When is the beginning of the Middle Ages?" does require historical reasoning when combined with "What do you think?" and "Give reasons for your opinion." Using historical reasoning a student could argue that the Middle Ages started about $500 \mathrm{AC}$, or, perhaps, earlier or later and why so.

There is hardly any empirical research available about the way students interpret historical questions with which they are confronted in the history lessons, about the kind of questions they ask when engaged in a particular learning activity, or about how questions guide historical reasoning. Wineburg (1998), in a descriptive study of how two historians with high and low background knowledge read and interpret primary source documents, states that understanding emerges as a result of a dialectical process between the questions that are asked and the textual materials that are encountered. In an exploratory study of how experts and novices in the domain of history try to date and interpret a cartoon from the Cold War period, we found that questioning was an important means to build a historical context and that persons with more expertise within the domain were more inclined to ask questions (Van Boxtel and Van Drie 2004). Halldén (1998) warns that students may have difficulties finding the "correct" interpretation of historical questions asked in the classroom. First, questions may be ambiguous. For example, the question of how a specific event came about may be interpreted as a quest for the enabling factors, a quest for the factors that made the event come about, or a quest for a narrative in which the event is depicted as a consequence of a larger chain of events. Second, students, who are not yet completely socialized into the genre of school history, use their own conceptions and frameworks to interpret a question and these may differ from those of teachers and historians. Van Drie et al. (2006) compared how students reasoned when working on an evaluative question compared to an explanatory question. It turned out that the evaluative question elicited more historical reasoning, including argumentation, description of change and continuity, and explanation. This finding suggests that some questions may be more powerful to provoke 'rich' historical reasoning than others. 
To summarize, asking historical questions in the context of historical reasoning concerns asking descriptive, causal, comparative, or evaluative questions about historical phenomena and about the sources that give information about the past.

The example in Fig. 2 illustrates how questions can function as an engine for historical reasoning. The example is taken from a small scale study that explored historical reasoning in dyads of students (12 years of age) and in subsequent whole-class discussions about the same task (Van Boxtel 2002). The task involved a medieval picture showing armed men on horses and men on foot leaving a castle. The students were asked to write a caption for this picture using some of the concepts that were given next to the picture. The episode below is taken from a whole-class discussion. In the analysis of the whole-class discussions we coded types of historical reasoning: describing processes of change and continuity, comparing historical phenomena, and explaining historical phenomena. When one of the students, Mary, mentions that in those days peasants had to work for the nobility, the teacher brings in the term system and asks an explanatory question: "Why did these people obey to this system?" (line 10). The teacher initiates a causal reasoning that is coconstructed by himself and the students Mary and Femke (lines 11 to 22).

\section{Using sources}

Information about the past is acquired by a whole range of different types of sources, such as all kinds of written documents, images, and objects. A distinction can be made between primary sources from the time of the event itself and secondary sources or historical accounts of the events. Although objects and images contain more different information about the past than written sources (Fasulo et al. 1998), in educational settings students are often confronted with the latter. These sources may be primary as well as secondary and can be rather diverse: accounts of historians, excerpts of diaries and letters, treaties, and so on. When talking here about the sources, we refer to primary and secondary sources, written sources as well as images. Information from the sources is important to support assertions about the past. Sources often contain complementary, but also contradictory information about the past. As a consequence, the contents of several documents cannot be simply combined into a single representation (Rouet et al. 1996) and specific knowledge about documents and methods must be acquired to evaluate the trustworthiness of the sources. Rouet et al. make an important distinction between reasoning about documents and reasoning with documents. Reasoning with documents refers to the ability to use document information when executing a historical inquiry. Reasoning about documents refers to the activity in which a document is evaluated on the basis of the type of document it is.

Reasoning with textual sources has been extensively studied (e.g., Leinhardt and McCarthy Young 1996; Perfetti et al. 1995; Stahl et al. 1996; Wineburg 1991a, b, 1994, 1998). Wineburg (1994) found that historians make three types of cognitive representations when reading historical texts: of the text, of the event, and of the subtext (i.e., the text as rhetorical artefact). He also found that students approach historical documents in a different way than expert historians. In an earlier study he compared how eight historians and eight high-school students reasoned about several primary sources (Wineburg 1991a). From the thinking-aloud protocols three heuristics related to the study of historical documents were identified: (a) contextualization, or the act of situating a document in a concrete temporal and spatial context; (b) sourcing, or the act of looking first at the source of the document before reading the body of the text; and (c) corroboration, or the act of comparing documents with each other. Most differences between historians and students could be related to different belief systems. Firstly, historians and students had different beliefs about 
Fig. 2 Excerpt of a whole-class discussion in which a collaborative reasoning is initiated by a historical question
Mary

You can see knights with armor, a lance, a shield and a

sword

2 Mary The serfs walk in front of the knights,

3 Mary those are a kind of peasants who work for the nobility

4 Mary and they had to till the ground of that nobility

5 Teacher Yes

6 Teacher Yes, guys, Mary actually mentions a lot of good things

7 Teacher And now the question, why did these people do this?

8 Teacher Because, we don't have this system anymore, we don't know this

9 Teacher Perhaps it is interesting to see how this system developed

10 Teacher Why did people obey this system?

11 Mary Yes, they benefited from it as well

12 Mary When they tilled the ground they got food

13 Mary Yes, they had to pay a little bit for it

14 Mary And they also got protection

15 Teacher Can you repeat that, when they...?

16 Mary Yes, when they tilled the land, they got food

17 Teacher Who do you mean by 'they'?

18 Mary The serfs till the land for the nobility

19 Teacher The serfs till the land for the nobility

20 Femke (raises her hand)

21 Teacher Do you want to add something to this answer or want to make a change?

22 Femke When the serfs tilled the land of the castle, in return, they got protection of the castle in case they were attacked themselves

the task. The central question was "Which painting most accurately depicts what happened in Lexington?" Students approached the task as if one answer was correct and they had to find it. Historians, on the other hand, opposed the question with comments like "What did actually happen? What was actually going on there?" Their final result was more a suggestion than an answer. Secondly, in the reconstruction of the event, historians were more able to take into account the matter of where and when things happened. A third difference was related to beliefs about the texts, the conception of the primary documents. Whereas historians considered information about the text, such as who wrote the text and at what time, to be very important, students focused on the information in the text. Reading 
texts seemed to be a process of gathering information for students, with texts serving as bearers of this information. On the other hand, historians seemed to view texts as social exchanges to be understood, puzzled about the intentions of the author, and situate the text in a social context. All this means that to historians what is said is inseparable from who says it. As a consequence, historians more often made use of the sourcing heuristic. A fourth difference was found in the corroboration heuristic, or in the beliefs about the nature of historical evidence. For historians, corroboration was indispensable because every account was seen as reflecting a particular point of view. They were mainly concerned with the question of how a source's bias influences the quality of the report. Students seemed to view bias as an attribute of some texts but not of others. In addition, the students also gave more importance to textbooks, whereas the experts ranked primary sources higher (cf. Rouet et al. 1998). According to Wineburg, the differences between students and historians resulted not so much from a difference in knowledge about the subject at hand, as not all the historians specialized in the topic at hand and some students showed more factual knowledge about the topic, but from a difference in knowledge and thinking skills about historical evidence. Historians were able to reason thoughtfully about the accuracy of the documents and were in this way able to build up an elaborate model of the event at hand. Wineburg's study suggests that high-school students do not spontaneously use contextualization, sourcing, and corroboration heuristics when reading documents.

All the studies mentioned above involved students from high school and college. Lee and Ashby (2000) studied children's changing ideas about historical evidence between the ages of seven to fourteen. Based on extensive studies that included 320 students, they identified six steps in students' ideas about accounts and their relation to the past, namely (a) the past as given, (b) the past as inaccessible, (c) the past as determining stories, (d) the past as reported in a more or less biased way, (e) the past as selected and organized from a viewpoint, and finally (f) the past as (re-)constructed in answer to questions in accordance with criteria. Students often treated the sources as information and only used that information which supported the claim. Information from the sources was neither critically discussed, nor compared to information from other sources (Ashby 2004). These outcomes are in line with the results found by Wineburg.

We define the use of sources in the context of historical reasoning as the evaluation of sources (e.g., their usefulness, trustworthiness) in relation to the question at hand and the selection, interpretation, and corroboration of information from sources in order to answer a historical question or to provide evidence for a claim about the past.

The example in Fig. 3 shows two students discussing the content of a document, taken from a study on how students reason about the past in a computer-supported collaborative environment (Van Drie 2005; Van Drie et al. 2005). Participants were students from preuniversity education, 16-17 years of age. Each student worked on his or her own computer, physically separated from the partner, and communication took place by chat and other shared tools. The computer-learning environment enabled students to collaborate in pairs on a historical inquiry task, which included studying historical sources and writing an essay of 1,000 words. The task, which took $6 \mathrm{~h}$, was about the question "Were the changes in the youth culture in the nineteen sixties in the Netherlands revolutionary or not?" The chat discussions in this study were, among others, coded in elements of historical reasoning, for example contextualization, describing changes, argumentation, and use of sources. The excerpt below is one that was coded as use of sources. In the original study this excerpt was not analyzed in more detail. When considering this excerpt in relation to the definition of use of sources in the context of historical reasoning, the following can be noticed: Rosa and Wilma try to find out whether the historian, which is cited in source 22, thinks the changes 
of the sixties were revolutionary or not and use this in their argumentation. However, they do not relate the historians' viewpoint in this fragment to other views of historians, neither do they consider the context of the source or evaluate the trustworthiness of this source. Of course, only a small part of the complete chat discussion is shown here and coming to conclusions on how these two students used historical sources in general would require taking into account the complete chat discussion, as well as the products they made. The excerpt, nevertheless, provides an example of how two students deal with sources in the context of an inquiry task.

\section{Contextualization}

The past is strange and familiar at the same time (Wineburg 2001). In order to interpret historical events, one has to apply a wide range of general knowledge of how social variables function and interrelate these in order to interpret the specific events under consideration (Kuhn et al. 1994). But understanding and interpreting historical events and acts of persons also requires knowledge of the specific historical context, which is formed by the characteristics of the time and place of the event. It requires finding the appropriate historical context and, then, interpreting the phenomenon in accordance with that context (Halldén 1997). When talking about contextualization, Wineburg (1998) deliberately uses the term "creating" historical contexts, instead of "placing" or "putting" something into context, verb forms that conjure up images of jigsaw puzzles in which pieces are slotted into pre-existing frames. He refers to the Latin contextere, which means to weave together, to connect strings in a pattern. De Keyser and Vandepitte (1998) distinguish different frames of reference that can be used to contextualize a historical phenomenon: (a) a chronological frame of reference, including knowledge of periods, significant events, and

Fig. 3 Excerpt of a chat discussion in which students reason about a source
Rosa source 22 is rather vague to me because he mentions so many features

2 Rosa It's not really a change what he describes

3 Wilma the end of an era and the beginning of a new era [quotes from the document]

4 Rosa that sounds nice

5 Wilma yeah it does, but that's a change then, isn't it...?

6 Rosa But he doesn't think it's revolutionary because he says that when it comes to representation, the Sixties are heavily exaggerated

7 Wilma that's a good one...

8 Rosa so it's not all that much according to him

9 Wilma Then I'll put that one in

10 Rosa That's something you can work with

11 Rosa ?

12 Wilma Yes, that's a good answer to me... don't you think it is?

13 Rosa Yes, fine, I'm not very good at source work 
developments; (b) a spatial frame of reference, including knowledge about locations and scale; and (c) a social frame of reference, including knowledge of components of human behavior and social activity such as socio-economic, socio-political, and socio-cultural conditions of life. The chronological frame is especially fundamental in history, as it is the main organizing principle. Stow and Haydn (2000) point out that chronology in history education does not only refer to the sequencing of events, but also to a general understanding of historical time, such as dating systems and time-related vocabulary.

Only few empirical studies have focused on contextualization and on how it is shaped by historical knowledge, thinking strategies, and epistemological beliefs. Based on a series of interviews with adolescents, Shemilt (1983) concluded that adolescents have special difficulty in making sense of the story in which the particular events and episodes are located. He compares it with students who are able to talk sensibly about certain scenes and characters of a play, but having no idea what the play is about. The failure to grasp the nature of historical context is often described as an important source of student misunderstanding (Wineburg 2001; Husbands 1996). Novices in the domain find it difficult to try to think about the past in its own terms and not to judge past actors and actions solely by present standards. Often, one must be able to imagine oneself in situations that he or she is not likely to experience (Spoehr and Spoehr, 1994). This ability is referred to with the term empathy. In the CHATA project carried out by Lee et al. (1997) in primary and secondary schools in England, children's ideas about explanation and inquiry in history were investigated. One of the outcomes of this project was the model of progression for rational understanding in history, in which contextualizing and empathy are important aspects. The lowest level is what they call The Divi Past: past action is unintelligible because people in the past were 'divi' -stupid, not as clever as we are, inept, morally defective, or 'didn't know any better.' Students in a more advanced level begin to view history as an explanatory system but make little attempt to understand the past in its own terms. At the highest level called contextual historical empathy, actions of people in the past are set in a wider context of beliefs and values. It is recognized that there are differences between the mindsets of the past and the present. According to Lee et al., only from the age of 11 to 14 , some students are beginning to distinguish between what they know about the situation and what the historical agent knew at that time.

In an expert/expert study Wineburg (1998) describes in detail how two historians build a historical context. He compared the interpretation of historical texts about Abraham Lincoln of a historian who was a specialist in the Civil War period and a historian in the general field of American history. Based on the outcomes of the study, six different types of contextual comments were distinguished: (a) spatio-temporal comments, about the physical location and temporal sequence of events; (b) social-rhetorical comments, about social demands of situations, intellectual, and ideological landscapes; (c) biographic comments, about life histories of individuals; (d) historiographic comments, about the body of historical writing about the past, (e) linguistic comments, about historical meanings of words, terms, and phrases; and (f) analogical comments, drawing explicit comparisons to other historical periods. For the more knowledgeable historian, the documents activated broad associations and extensive declarative knowledge that let him situate documents in a web of chronologically ordered events. Both historians were able to create a context. A more knowledgeable historian used a broader range of ways to do so, for example, through knowledge of the life history of Lincoln, the historical meaning of words, terms, and phrases and comparisons to other time periods. It was concluded that it was not only the factual knowledge that helped the historians to create a historical context, but also the awareness that words give rise to 
multiple interpretations. The historian that brought more background knowledge to the task and had more resources for building a context raised more questions about his knowledge and showed more doubt.

Currently, not much is known about the kind of knowledge that helps students to contextualize. Van Boxtel and Van Drie (2004) focused on the prior knowledge that novices (students) and more expert persons (history teachers) in the domain of history use to build a historical context for an unknown document or picture from the past in order to date it. Students who managed to date the sources correctly used (a) knowledge of significant historical events or so-called landmarks, such as the abolition of slavery; (b) a rich network of related and colligatory historical concepts, such as concepts related to communism or the Roman empire; and (c) knowledge of periodization and narrative structures, such as the rise and fall of the Roman empire and the beginning and the end of the Cold War.

To conclude, in the framework of historical reasoning contextualization is defined as situating a historical phenomenon, an object, statement, text, or picture in a temporal, spatial, and social context in order to describe, explain, compare, or evaluate it.

Figure 4 gives an example of contextualization in the context of interpreting and dating a historical cartoon from the Cold War period. The cartoon is about Stalin's proposal in 1952 to unite and neutralise Germany. The aim of study was to investigate which means novices (students in several grades) and experts (in our study history teachers) use to interpret an unknown historical document or picture (Van Boxtel and Van Drie 2004). The students and teachers worked in pairs and their conversations were videotaped and transcribed. We coded the conversations on the utterance level using a coding scheme that focused on the identification of important ingredients of contextualization, as, for example, making reference to characteristics of time, space, and social context. Lara and Sanne are 16-year old pre-university students. In line 11 Lara starts to build a context for what she and Sanne see on the cartoon. The contextualization episode that follows contains several statements in which reference is made to different types of knowledge that is used to build a historical context, as, for instance, knowledge of a particular period (Cold War, line 11), knowledge of characteristics of a location (Germany was divided during the Cold War, line 11), and knowledge of a particular event (Russia tried to make the East communist, lines 13 and 15).

\section{Argumentation}

Because historical accounts are based upon various kinds of sources that often contain partial and contradictory information and because historical interpretations are not definite, assertions and claims about the past must be supported by rational arguments, which, in turn, should be based upon well-evaluated evidence. Historical reasoning does not mean just giving an opinion or a viewpoint; it is the arguments and evidence used to support the opinion that counts (cf. Barton and Levstik 2004; Spoehr and Spoehr 1994). The skill of argumentation is, therefore, fundamental to historical reasoning (cf. Voss and Means 1991). Reasoning in the domain of history can be considered as informal reasoning. Contrary to formal reasoning, informal reasoning is related to ill-structured problems. Conclusions are reached on the basis of weighing arguments and evidence. They are never definite, but only more or less probable, as new evidence can alter these probabilities (Kuhn 1991; Voss et al. 1991). Voss et al. mention three criteria for evaluating the soundness of informal reasoning. These criteria include (a) whether the reasoning providing support is acceptable or true, (b) the extent to which the reason supports the conclusion, and (c) the extent to which an individual takes into account reasons that support the contradiction of the conclusion, also known as counter argumentation. In relation to argument-based reasoning in history, 
Fig. 4 Excerpt of a discussion in 1 Lara which students build a historical 2 Sanne context that cat is communism

that cat liberates that angel to make peace with the mice, or something like that

yes

Look at [points] all these countries, they are not communist, these are communist, aren't they? Poland, Czechoslovakia...

5 Sanne yes, they are taken by the Russians, yes

6 Lara these are

7 Sanne perhaps they try to catch it with that small angel [points], or something like that

8 Lara yes that it is a trap

9 Sanne yes, a trap, yes I think so

10 Sanne thus it is

11 Lara and in the Cold War.. Germany was divided then, wasn't it?

12 Sanne yes

13 Lara and with that wall, that ehm Russia also had the East and tried to make it communist, isn't it?

14 Lara that was the case in the Cold War

15 Lara in the Cold War they tried to make Germany a communist country

16 Sanne yes

Perfetti et al. (1995) maintain that sound reasoning requires awareness that (a) arguments require evidence, (b) evidence is documented, and (c) documents are not equal in their privilege as evidence. The process of argumentation is, thus, closely related to the use of sources.

Research has shown that, although people in general are able to support their claims with arguments, even from a young age onwards (Stein and Miller 1993), weaknesses can be found in relation to the generation of different types of arguments (Voss and Means 1991), taking into account of counterarguments, and weighing of different theories (Kuhn 1991). Research in the domain of history shows the same pattern. For example, Pontecorvo and Girardet (1993) found that discussions between 9-year old students, who were asked to reach agreement about a historical claim, largely consisted of claims and justifications for these claims. Our own findings in a study on writing argumentative texts in history showed that most students (pre-university level) only mentioned several arguments in support of their claim, with hardly any counterarguments given, and with no weighing of arguments pro and contra (Van Drie et al. 2006). In their study of children's changing ideas about historical evidence between the ages of seven to fourteen, Lee and Ashby (2000) also found that students often treated sources as information and only used the information which supported their claim. Spoehr and Spoehr (1994) argue that taking into account counterarguments is a very difficult aspect of reasoning in the domain of history.

Kuhn et al. (1994) relate the differences in level of argumentation to epistemological beliefs and discerns a progression of epistemological understanding. Initially, at the first level historians' accounts of events are not distinguished from the events themselves: the subject focuses on statements about the events themselves, meta-statements about the accounts are rare, and two different accounts are not compared but information is added to provide a more complete version. In the second level, different accounts are seen as 
genuinely different: differences are attributed to wilful misrepresentation or bias on the part of one of the historians, and a neutral, third party is seen as capable of discerning the "truth." Leadbeater and Kuhn (1989, in Kuhn et al. 1994) found that only one quarter of sixth graders showed this second level of reasoning. In the third level subjects maintain that both accounts could be right, because everyone sees things from their own point of view: all accounts are regarded as opinions. This level appeared in the study of Leadbeater and Kuhn among ninth graders and became the most frequent stance by the twelfth grade. Furthermore, they observed two subsequent levels of reasoning among adults. At one level, an objective reality is regarded as ultimately known through critical evaluation of multiple accounts. At the other, the realm of facts exists only as interpreted by human observers and do not yield a single reality.

To conclude, as a component of historical reasoning, argumentation concerns putting forward a claim about the past and supporting it with sound arguments and evidence through weighing different possible interpretations and taking into account counterarguments.

Figure 5 shows an example from an essay written by Rick and Joni in a text-editor in an electronic learning environment from the same study as the example in Fig. 3 in the section on using sources (Van Drie 2005). This essay gained a relatively high score for argumentation. In their complete essay, only one section of which is included in the example, they take the standpoint that the sixties were revolutionary and not only support this standpoint with several arguments but also discuss counterarguments and try to refute them. In the example, Rick and Joni discuss the fourth counterargument in which they refer to the fact that most radical youth was located in Amsterdam, and that Provo (a protest group) was not as revolutionary as is commonly assumed. They discuss whether the actions of Provo were unique or more general, which is an important disciplinary heuristic when reasoning about processes of change and continuity. The students also refer to information in one of the sources, a text written by a Dutch historian and make a meta-statement about this source when they conclude the source to be trustworthy. Although the remark "a man who should have knowledge on this subject" might not be a very strong argument, the fact that this remark is made shows that these students have some understanding that not all the documents are equal in their privilege as evidence. In the last sentence of the example, Rick and Joni try to refute this counter-argument by stating that this is only the viewpoint of one historian. Again, this might not be a strong argument, but it shows that they understand that they can't trust on the argument of one person and need to be open for alternative interpretations.

\section{Using substantive concepts}

Each domain has its own language. Discipline-bound concepts are "tools" to think about, question, describe, analyze, synthesize, and discuss historical phenomena. Husbands (1996) describes concepts as the grammar of history, as they have the power to organize the infinite number of facts that characterize history. Student understanding and use of historical concepts is one of the major goals of history education. A distinction can be made between methodological and substantive concepts. Methodological, second order concepts (Lee et al. 1998), or meta-concepts (Limón 2002) refer to the methods used by historians to investigate and describe historical processes and periods and will be described in the following section. Substantive concepts refer to historical phenomena, structures, persons, and periods (e.g., pharaoh, feudalism, Charles V, Enlightenment). Different types of substantive concepts are used in history. Haenen and Schrijnemakers (2000) distinguish between unique and inclusive concepts. A unique concept applies to a thing, person, event, 
Fig. 5 Fragment of an essay in which students put forward claims and support them with arguments
Fourth, most of the actions took place in Amsterdam, a city that was much more progressive than the other parts of the country. Therefore, in Amsterdam, many actions took place and here Provo was founded. Provo took part in the city council elections and won one seat (source 15). The most famous plan of Provo was the 'White Bicycle Plan'. They wanted to have public bicycles, without a lock or deposit. In this way they wanted to get rid of the cars in the city centre of Amsterdam. Provo was not that innovative and revolutionary. The way in which Provo expressed itself was new, however, their ideology and values had strong roots in the past, as it is said in source 22. Historian Pas, a man who should have knowledge on this subject, summarizes it as follows: "We should see Provo, more than we did up to now, as an amalgation of generations, traditions and ideals."(These ideals have been the same throughout the years, though the form in which they were expressed changed.) Still, this is the opinion of one person, and we have to be careful with drawing general conclusions.

or period each of which is the only one to which the name applies (e.g., D-day, Middle Ages, Peace of Westfalia). Inclusive concepts are concepts that cover instances to which these names apply (e.g., castle, depression). Halldén (1997) points to the fact that in history many so-called colligatory concepts are used; higher order concepts that bring a series of events together by describing them from an aspect that makes them intelligible or relevant in an explanation. Examples are the fall of the Roman Empire, Renaissance, Enlightenment, and Industrial Revolution. Such concepts provide a thematic organization of historical knowledge.

Students face various problems in understanding and using substantive concepts (Van Drie and Van Boxtel 2003). The first problem is that historical concepts are often abstract and theoretical. They do not refer to concrete objects in the past and are given meaning in the context of related concepts within a conceptual network. For example, to explain the concept of democracy, other concepts must be used, such as parliament, representation, and government. Each of these concepts is abstract and difficult to understand. The second problem is that substantive concepts often have no fixed meaning. This is related to the fact that historians themselves differ in their interpretation of concepts (Ankersmit 1982) and that the discipline of history does not have a large specialized vocabulary and uses concepts taken from other disciplines (e.g., economics, politics, and sociology) and from everyday life (Berti 1994). Concepts used in everyday life often have a different meaning in the past. For example, trade meant something different in the Middle Ages than it means in our present Western society. Thus, the meaning of concepts differs in time and place, and students must learn to describe phenomena that are different from those experienced in the present with known terms. Students often interpret a concept on the basis of their knowledge at present time and, thus, easily develop misunderstanding or misconceptions through anachronism. In addition, some concepts, such as fascism or slavery, give rise to strong feelings, making it sometimes difficult to distinguish between moral judgment and historical explanation (Von Borries 1994). Students should, thus, learn to differentiate between the present meaning of concepts and the meaning of concepts used in a specific historical context. The third problem arises from the fact that some concepts may be very specific and related to one period, so students may come across them only a few times, which limits their opportunities to understand and learn these concepts (Berti 1994). Finally, Limón 
(2002) points out that historical concepts are often implicit and not presented in an isolated way, but within a narrative. Students often have to infer their meaning, which may give rise to misunderstandings.

Relatively little research has been conducted into students' ideas on particular substantive concepts (Limón 2002). The studies that did focus on students' concept knowledge found that this knowledge is limited. Berti (1994), for example, notes that students' use of concepts does not guarantee the correct understanding of their meaning. McKeown and Beck (1990) studied young students' knowledge about the American Revolution just before and a year after they studied the subject in schools. They found that students in both groups were only able to provide simple associations with the concepts, as well as simple links between ideas, and that there were a lot of misconceptions and confusions. Others have shown that conceptual understanding in history is related to one's social experience and culture (Delval 1994; Torney-Purta 1994). Especially younger children, having only limited social experience, may have difficulty in understanding historical concepts.

To conclude, using substantive concepts in historical reasoning concerns the use of concepts that name historical phenomena, persons, and periods when organizing information about the past in order to describe, compare, and/or explain historical phenomena.

The example which is presented in Fig. 2 also shows how substantive concepts shape reasoning in a whole-class discussion. In our analysis of the discourse we distinguished reasoning episodes with and without substantive concepts relevant to the task at hand. The group task that is discussed was successful in provoking student reasoning with substantive concepts, as students transformed their more everyday language into the language of history. For example, students first (not in the excerpt) talked about "men with armour" and "peasants" and then about "knights" (line 1) and "serfs" (line 2). The students use the terms knights, serfs, and nobility and the teacher brings in the abstract term system (which he explains later on the discussion) in order to explain why peasants worked for the nobility. In lines 3 and 4 Mary gives a description of the concept serf. The concepts nobility, serfs, and feudal system are important tools in the explanation of the actions of concrete persons in the Middle Ages.

\section{Using meta-concepts}

As described in the previous section, meta-concepts are related to the methods used by historians to investigate and describe historical processes and periods. Limón (2002) for example, mentions evidence, cause, explanation, empathy, time, space, change, source, fact, description, and narration. She argues that these meta-concepts form the basis of historical knowledge and mediate students' understanding of substantive concepts. Research has shown that students' knowledge about these meta-concepts is often implicit (Lee et al. 1998). Voss et al. (1998) found that although college students did seem to have some understanding of methodological concepts, this understanding was not well integrated.

We discuss meta-concepts in relation to historical reasoning: meta-concepts guide the asking of questions about the past as well as the description, comparison, and explanation of historical phenomena and the use of sources in an argumentation. In our framework we consider the use of meta-concepts in historical reasoning as the application of disciplinebased heuristics that help to describe processes of change and continuity, to compare, and to explain historical phenomena. Meta-concepts and heuristics related to the use of sources, as, for instance, evaluating the trustworthiness and corroboration of information from different sources, were discussed in the section about sources. 
According to Stearns (1998), understanding the phenomenon of change over time is the main purpose of history. He describes historical change as a multifaceted or multi-layered subject, which can occur in very different areas of society, for instance, political systems, technologies, fundamental beliefs, and family life. Historians often distinguish between political, economical, social, and cultural changes. Studying historical changes also raises questions about how change came about, whether it came about gradually or suddenly, as well as questions about the impact of changes and continuity or discontinuity. Barton (2001) showed that the socio-cultural setting of history education is an important factor shaping the focus on the role of individuals as agents in historical change. In a comparison of the reasoning of students from the United States with that of students from Northern Ireland, he found that US students particularly emphasized the role of (famous) individuals in bringing about change, whereas the Northern Ireland students gave more attention to societal factors such as political and social movements, economics, and the government.

The use of comparison to analyse and organise information about the past implies a focus on aspects of similarity and differences. Comparison as a heuristic can help to separate extraordinary situations or acts from more common ones. For example, in order to illuminate a particular political revolution, it can be helpful to compare it with other political revolutions. McCarthy Young and Leinhardt (1998b) studied a specific form of comparison in history classes: analogical reasoning. They make a distinction between direct historical analogies involving comparison with other historical phenomena (events, structures, or meta-systems) and contextual analogies in which a historical phenomenon is compared to a familiar base drawn from personal or shared experience. Direct historical analogies are especially helpful to explain what something was, whereas contextual analogies tend to explain what something meant. Though overgeneralization and misleading comparison are potential risks of such analogical reasoning, McCarthy Young and Leinhardt did not find this kind of "misuse" in the classes of the three history teachers they studied.

In case of explanation, it is often stressed that causation in history does not involve simple cause-effect relationships: instead, many actions and events occurring over time could play a role in producing a historical event. A distinction can be made between immediate and long-term causes and between manifest and latent events or long-term developments, such as population shift or climate change (Spoehr and Spoehr 1994). Jacott et al. (1998) describe two different theoretical models of explanation in history. The intentionalist model conceptualizes historical explanation basically in terms of human actions, attributing major importance to the particular motives, intentions, and beliefs of the agents involved. The structural model of explanation is based on the relationship between a set of conditions (e.g., economic, demographic, social, political, religious) that constitute social reality. Thus, in case of explaining, historians search for more than one cause and/or for more than one type of cause. Results from several studies show that students tend to explain historical events from the intentionalist, personalistic point of view (e.g., Carretero et al. 1997, 1994; Halldén 1993). In the study conducted by Carretero et al. (1997) novices and experts were asked to explain four historical events by ranking six different types of causes in order of importance (political, economic, ideological, personalistic, remote, and international policy). The results showed that non-experts attributed greater importance to personalistic causes. This is in line with findings of Rivière et al. (1998) that show that personal factors are better recalled, especially in lower levels of education. Experts tend to vary the importance given to different causes according to the historical event in question. They do not attribute the same influence to political, economic, and cultural-ideological causes, but consider each event in its own context. In short, when explaining the past, students face difficulties in using multiple and different types of causes, often have 
difficulties in realizing that some event can be a cause and a consequence at the same time (Shemilt 1983), and tend to maximize the role of human action over the influence of institutional factors.

To summarize, using meta-concepts in historical reasoning involves using heuristics related to (a) the description of processes of historical change, for example distinguishing change and continuity, gradual and sudden changes, and political, economical, social, and cultural changes; (b) the comparison of historical phenomena, for example distinguishing similarities and differences and unique and generic aspects; (c) the explanation of historical events, for example the identification of multiple causes, types of causes, relationships between causes, and of long term and immediate consequences; and (d) the use of sources providing information about the past, for example evaluating the trustworthiness of the source and corroborating information from different sources (see also the section about the use of sources).

Figure 6 presents a fragment of an essay written in a text editor in an electronic learning environment by two students, taken from the same study as the example shown in Fig. 3. Pairs of students worked on the question of what caused the changes in the behaviour of Dutch youth in the nineteen sixties (Van Drie 2005, 2006). The fragment shows the organization of information from several documents in an explanation. In this study, the scoring of the essay took, among others, into account the amount of causes given and the quality of the description of the causes (e.g., are different types of causes mentioned, are the different causes interrelated, is a distinction made between long term and immediate consequences?). This fragment forms the conclusion of their essay, which shows that these students are aware that there is not a single cause that explains the changes in the behaviour of the youth in the nineteen sixties. They take into account multiple causes and distinguish different types of causes (e.g., World War II, social-economic developments, and a changing mentality). They identify the Second World War as an important cause, together and in relation with societal developments. In the first sections of the essay (not presented here) the students are more specific about these societal developments, where they mention, for instance, increasing welfare, more education for youngsters, and the influence of television, and explain how these causes relate to changes in the youth culture.

\section{Reasoning or Historical Reasoning?}

Having explored historical reasoning in more detail, the question may arise to what extent there is something like historical reasoning or whether it merely reflects general reasoning skills. This question is related to the fundamental question whether thinking and reasoning are general skills or domain-specific skills. Kuhn (1991) argues that there is a general reasoning ability, which is independent of domain-specific knowledge. The philosophers in

Fig. 6 Fragment of an essay that reflects the use of heuristics related to the meta-concept cause
After reading and discussing a lot, we have come to the conclusion that there is no single cause for the changes of the youth in the fifties and sixties. There are more events that have caused the drastic change of youngsters in that period. One of the main causes is the war. After the Second World War people started to think differently. They experienced that it could go not the way they expected. Due to this awareness, together with societal developments, the behavior of the youth in the fifties and sixties changed a lot. 
her study, who are considered experts in reasoning with no specific knowledge in the domain, outperformed the domain experts on quality of reasoning. Better reasoners tend to be analytic, generate different types of arguments and also arguments opposed to ones own position, and they are more inclined to use meta-cognitive mechanisms. On the other hand there are findings that stress the domain-specific aspects (Glaser 1984; Hirschfeld and Gelman 1994; Perfetti et al. 1995; Voss et al. 1980, in Wineburg 1991a). Perfetti et al. (1995) state that historical reasoning may be informed by specific (historical) information but is guided by general reasoning principles. They consider historical reasoning as "neither specifically historical, nor fully general" (p. 5). Historical reasoning then depends on skills to approach texts and evidence critically and with an attempt to sort out evidence and construct arguments. We consider historical reasoning as a sub-concept of the overarching concept reasoning, just as, for instance, geographical reasoning or jurors reasoning. Historical reasoning can, thus, be regarded as a more specific form of reasoning. Consequently, historical reasoning requires general reasoning skills, but also contains several characteristics that are more specific to this particular domain. Historical reasoning is not only informed by historical information, domain-specific knowledge, and domainspecific epistemological beliefs, but also implies the application of historical heuristics or thinking strategies related to the meta-concepts of history. An example may clarify this. In one of our studies we asked both students and their history teachers to discuss in pairs and write a short essay about the question 'To what extent can Saddam Hussein and Adolf Hitler be compared?' that was given together with a text claiming that there were many communalities. Whereas the discussions and essays of the student dyads hardly reflected historical reasoning, those of the teachers did. The reasoning of the teachers was informed by a rich historical knowledge base that enabled them to judge carefully the claims made in the text, for example, two teachers criticized the claim that both Hitler and Hussein knew a personality cult, by discussing several characteristic features of the personality cult of Hitler and bringing in an alternative comparison with the personality cult of Stalin. The teachers did not only focus on communalities (arguments in favour) but also on differences (arguments against), always contextualizing features of the reign of Hussein and Hitler. Domain-specific epistemological beliefs seemed to underlie their reluctance to compare persons from different times and places and their careful analysis of the historical context of each person.

\section{Using the Framework in Empirical Research}

The framework of historical reasoning presented here helps guide future research. Firstly, the description of the components of historical reasoning shows that not all components have been investigated to the same extent and that some need further elaboration and specification. Although there is a reasonable number of studies which focus on heuristics related to the explanation of historical phenomena and the use of historical sources, there are not many empirical studies that focus on asking historical questions, contextualization, comparisons between historical phenomena, reasoning about historical changes, and the use of substantive concepts in reasoning. In addition, as far as we know, studies in which different components are more coherently studied are also still rare. Secondly, more insight is needed into the relationship between ways and levels of historical reasoning and historical knowledge, historical thinking strategies, and epistemological beliefs. The analytic framework presented here may provide a good starting point for investigating the question of the extent to which differences in reasoning are due to available historical and epistemological knowledge, strategies, and attitudes. Thirdly, historical reasoning is quite 
a complex activity and future research should shed more light on how to overcome the problems students face with historical reasoning, asking such questions as "What are good learning tasks that elicit and promote historical reasoning?" and "What are the effects of different learning tasks on students' reasoning?" As mentioned before, we have studied the effects of different inquiry questions and the role of the construction of different kind of external representations (e.g., diagram, list, and matrix). In future research projects we will focus on how whole-class discussions influence students' reasoning in small groups and on how students can be stimulated and supported to ask historical questions themselves.

\section{Using the Framework for Educational Practice}

Although the framework of historical reasoning was initially developed for research reasons, it can also be used by teachers in their daily classroom practice. Using the framework could help direct teachers' attention to the question of what students are supposed to do with the information about the past that they are confronted with. An important task of the teacher then becomes to create ample opportunities in the classroom for students to practice historical reasoning, for themselves, in dialogue with other students, and in dialogue with the teacher. Leinhardt, for example, showed that historical reasoning could be promoted by teacher-student conversations (Leinhardt 1993, 1997) and by writing tasks (Leinhardt 2000). In addition, Van Drie (2005) showed that collaborative learning in the context of an inquiry task could be a suitable instructional strategy to engage students in historical reasoning.

Clearly, teaching students to reason in history is a challenging job. It may take much time in an already time-limited practice of teaching several classes for only a few hours a week, it puts high demands on the reasoning skills of the teacher, it may be difficult and time-consuming to assess, and it requires good instructional materials and learning tasks (cf. O'Reilly 1991). The framework of historical reasoning presented here may provide a structure for the design of a curriculum and learning tasks. It could, for instance, be used to evaluate the current curriculum on how much time is directed to the various components. It may be a useful starting point for thinking about the desired goals students should attain in various school and age levels. In addition, the framework could be used to derive criteria for the assessment of students' products, such as essays.

\section{Conclusions and Discussion}

In this article a framework of historical reasoning was presented. This framework aimed at gaining more insight into historical reasoning and its' different components and at assisting the analysis of historical reasoning in the context of history education. Six components of historical reasoning were distinguished: (a) asking historical questions, (b) using sources, (c) contextualization, (d) argumentation, (e) using substantive concepts, and (f) using metaconcepts. From the literature on the components of historical reasoning we conclude that skilled historical reasoning can be described as reasoning which reflects contextualization or taking into account the historical period and setting, the use of substantive and metaconcepts to describe, compare, and explain historical phenomena, and sound argumentation based on a careful inspection and evaluation of available sources.

Historical reasoning, as described above, is a complex activity (cf. Fernández-Corte and García-Madruga 1998; Lowenthal 2000; Shemilt 2000; Spoehr and Spoehr 1994). 
Wineburg (2001) even describes it as an "unnatural act." Most research on learning history has been conducted at the level of high-school and university students, which has consequences for what might be expected of students, but it is clear that historical reasoning as such contains several problematic aspects for students. First, while discussing their claims, students tend only to use arguments supporting their own point of view, do not take into account alternative views, and have difficulties in weighing different arguments. A second, related problem is that students do not use sources extensively, do not consider the trustworthiness of the source, and hardly use corroboration of sources when studying historical documents. Thirdly, contextualization of historical problems requires detailed factual knowledge of the issue at hand and a broader chronological frame of reference, as well as knowledge of how people and societies function, which students may possess only to a limited extent. Fourthly, judging the past by its own standards and not by our present ones is difficult for students. Fifthly, in describing historical changes students often find it difficult to take into account processes of continuity and in explaining them, they face problems in using multiple and different types of causes, and tend to maximize the role of human action and minimize the role of institutional factors. Finally, many substantive concepts are difficult for students to understand and use in a correct way. From the perspective of individual differences, the level of historical reasoning appears to be related to several factors, as, for instance, age and development (e.g., Kuhn et al. 1994; Torney-Purta 1994), culture (e.g., Barton 2001; Delval 1994), working memory capacity (e.g., Fernández-Corte and García-Madruga 1998), and epistemological beliefs (e.g., Kuhn et al. 1994; Voss et al. 1998). In addition, specific content knowledge plays an important role (e.g., Leinhardt and McCarthy Young 1996; Perfetti et al. 1995; Wineburg 1998).

In this article we have provided some examples of how the framework of historical reasoning can be used to analyze historical reasoning in studies on teaching and learning history. These examples suggest that it is a useful tool to analyze students' historical reasoning in speaking and in writing and that it works in differentiating between different experimental conditions. Future research should focus on the validation of the framework and these outcomes may be considered as the first small step towards it. The framework can be used to analyze historical reasoning in more qualitative, as well as in more quantitative ways. As stated before, the framework does not specify fixed levels of historical reasoning. When it is desirable to specify levels of historical reasoning, the age and experience of students, the specific task, information, and support that are provided should be taken into account. For most of the components, there exists a reasonable amount of studies that would be helpful for such a specification.

To summarize, the proposed framework of historical reasoning suggests future empirical research on specific components as well as on their overall interrelations. Such research may support the development of instructional formats and principles to provoke and improve historical reasoning in history classrooms. At the same time, the framework can be used in educational practice as a framework to design and evaluate learning activities, learning materials, as well as criteria for assessment.

\section{References}

Ankersmit, F. R. (1982). Over geschiedenisonderwijs en historische begrippen [About history education and historical concepts]. Kleio, 8, 11-15.

Ashby, R. (2004). Developing a concept of historical evidence. Students' ideas about testing singular factual claims. International Journal of Historical Learning, Teaching and Research, 4(2), 44-55. Retrieved from http://www.ex.ac.uk/historyresource/journalstart.htm. 
Barton, K. C. (2001). A sociocultural perspective on children's understanding of historical change: Comparative findings from Northern Ireland and the United States. American Educational Research Journal, 38(4), 881-913.

Barton, K. C., \& Levstik, L. S. (2004). Teaching history for the common good. Mahwah, NJ: Erlbaum.

Berti, A. E. (1994). Children's understanding of the concept state. In M. Carretero, \& J. F. Voss (Eds.) Cognitive and instructional processes in history and the social sciences (pp. 49-76). Hillsdale, NJ: Erlbaum.

Booth, M. (1994). Cognition in history: A British perspective. Educational Psychologist, 29(2), 61-69.

Brown, A. L., Collins, A., \& Duguid, P. (1989). Situated cognition and the culture of learning. Educational Researcher, 18, 32-42.

Carretero, M., Jacott, L., Limón, M., López-Manjón, A., \& León, A. (1994). Historical knowledge: Cognitive and instructional implications. In M. Carretero, \& J. F. Voss (Eds.) Cognitive and instructional processes in history and the social sciences (pp. 357-376). Hillsdale, NJ: Erlbaum.

Carretero, M., López-Manjón, A., \& Jacott, L. (1997). Explaining historical events. International Journal of Educational Research, 27(3), 245-254.

Carretero, M., \& Voss, J. F. (Eds.) (1994). Cognitive and instructional processes in history and the social sciences. Hillsdale, NJ: Erlbaum.

Counsell, C. (2000). Historical knowledge and historical skills: A distracting dichotomy. In S. Capel, J. Davison, J. Arthur, \& J. Moss (Series Eds.) \& J. Arthur \& R. Philips (Vol. Eds.), Issues in subject teaching series. Issues in history teaching (pp. 54-71). London: Routledge.

De Keyser, R., \& Vandepitte, P. (Eds.) (1998). Historical formation. Design of vision. Brussel, Belgium: Flemish Board for Catholic Secondary Education.

Delval, J. (1994). Stages in the child's construction of social knowledge. In M. Carretero, \& J. F. Voss (Eds.) Cognitive and instructional processes in history and the social sciences (pp. 77-102). Hillsdale, NJ: Erlbaum.

Duffy, T. M., \& Jonassen, D. H. (1992). Constructivism: New implications for instructional technology. In T. M. Duffy, \& D. H. Jonassen (Eds.) Constructivism and the technology of instruction (pp. 1-16). Hillsdale, NJ: Erlbaum.

Fasulo, A., Girardet, H., \& Pontecorvo, C. (1998). Seeing the past: Learning history through group discussion and iconographic sources. In J. F. Voss, \& M. Carretero (Eds.) Learning and reasoning in history. International review of history education (Vol. 2) (pp. 132-153). London: Woburn.

Fernández-Corte, T., \& García-Madruga, J. A. (1998). Constructing historical knowledge at high school: The case of the industrial revolution. In J. F. Voss, \& M. Carretero (Eds.) Learning and reasoning in history. International review of history education (Vol. 2) (pp. 331-343). London: Woburn.

Glaser, R. (1984). Education and thinking: The role of knowledge. American Psychologist, 39, 933-104.

Goegebeur W., Simon, R., De Keyser, R., Van Dooren, J., \& Van Landegem, P. (1999). Historisch besef: Hoe waarden-vol?! Ontwikkeling van een Analyse-instrument [Historical Consiousness: How Valuable?! Development of an Instrument of Analysis]. Brussels, Belgium: VUB.

Haenen, J., \& Schrijnemakers, H. (2000). Suffrage, feudal, democracy, treaty... history's building blocks: Learning to teach historical concepts. Teaching History, 98, 22-29.

Halldén, O. (1993). Learners' conceptions of the subject matter being taught: A case from learning history. International Journal of Educational Research, 19, 317-325.

Halldén, O. (1997). Conceptual change and the learning of history. International Journal of Educational Research, 27, 201-210.

Halldén, O. (1998). On reasoning in history. In J. F. Voss, \& M. Carretero (Eds.) Learning and reasoning in history. International review of history education (Vol 2) (pp. 272-278). London: Woburn.

Hirschfeld, L. A., \& Gelman, S. A. (1994). Mapping the mind. Domain specificity in cognition and culture. Cambridge: Cambridge University Press.

Husbands, C. (1996). What is history teaching? Language, ideas and meaning in learning about the past. Buckingham, UK: Open University Press.

Jacott, L., López-Manjón, A., \& Carretero, M. (1998). Generating explanations in history. In J. F. Voss, \& M. Carretero (Eds.) Learning and reasoning in history. International review of history education (Vol. 2) (pp. 294-306). London: Woburn.

Jeismann, K. E. (1997). Geschichtsbewusstsein [Historical Consiousness]. In K. Bergmann, K. Fröhlich, A. Kuhn, J. Rüsen, \& G. Schneider (Eds.), Handbuch der Geschichtsdidaktik [Handbook of Didactics of History] (pp. 42-44.). Germany: Kalmeyersche, Seelze.

Kuhn, D. (1991). The skills of argument. Cambridge: Cambridge University Press.

Kuhn, D., Winestock, M., \& Flaton, R. (1994). Historical reasoning as theory-evidence coordination. In M. Carretero, \& J. F. Voss (Eds.) Cognitive and instructional processes in history and the social sciences (pp. 377-402). Hillsdale, NJ: Erlbaum.

Lee, P. (2004). Historical literacy: Theory and research. Paper presented at the History Education International Research Network Conference. Ambleside: UK. 
Lee, P. (2007). From national canon to historical literacy. In M. Grever, \& S. Stuurman (Eds.) Beyond the canon. History for the Twenty-first Century (pp. 48-62). Basingstoke: Palgrave Macmillan.

Lee, P., \& Ashby, R. (2000). Progression in historical understanding among students age 7-14. In P. N. Stearns, P. Seixas, \& S. Wineburg (Eds.) Knowing, teaching, and learning history. National and international perspectives (pp. 199-222). New York: New York University Press.

Lee, P., Dickinson, A., \& Ashby, R. (1997). "Just another emperor": Understanding action in the past. International Journal of Educational Research, 27, 233-244.

Lee, P., Dickinson, A., \& Ashby, R. (1998). Researching children's ideas about history. In J. F. Voss, \& M. Carretero (Eds.) Learning and reasoning in history. International review of history education (Vol. 2) (pp. 277-251). London: Woburn.

Leinhardt, G. (1993). Weaving instructional explanations in history. British Journal of Educational Psychology, 63, 46-74.

Leinhardt, G. (1997). Instructional explanations in history. International Journal of Educational Research, $27(3), 221-233$.

Leinhardt, G. (2000). Lessons on teaching and learning in history from Pauls' pen. In P. N. Stearns, P. Seixas, \& S. Wineburg (Eds.) Knowing, teaching, and learning history. National and international perspectives (pp. 223-245). New York: New York University Press.

Leinhardt, G., Beck, I. L., \& Stainton, C. (Eds.). (1994). Teaching and learning in history. Hillsdale, NJ: Erlbaum.

Leinhardt, G., \& McCarthy Young, K. (1996). Two texts, three readers: Distance and expertise in reading history. Cognition and Instruction, 14(4), 441-486.

Leinhardt, G., Stainton, C., \& Virji, S. M. (1994). A sense of history. Educational Psychologist, 29(2), 7988.

Leinhardt, G., Stainton, C., Virji, S. M., \& Odoroff, E. (1994). Learning to reason in history: Mindlessness to mindfulness. In M. Carretero, \& J. F. Voss (Eds.) Cognitive and instructional processes in history and the social sciences (pp. 131-158). Hillsdale, NJ: Erlbaum.

Limón, M. (2002). Conceptual change in history. In M. Limón, \& L. Mason (Eds.) Reconsidering conceptual change. Issues in theory and practice (pp. 259-289). Dordrecht, The Netherlands: Kluwer.

Lowenthal, D. (2000). Dilemmas and delights of learning history. In P. N. Stearns, P. Seixas, \& S. Wineburg (Eds.) Knowing, teaching, and learning history. National and international perspectives (pp. 63-82). New York: New York University Press.

Maggioni, L., Alexander, P., \& VanSledright, B. (2004). At a crossroads? The development of epistemological beliefs and historical thinking. European Journal of School Psychology, 2(1-2), 169197.

McCarthy Young, K., \& Leinhardt, G. (1998a). Writing from primary document. A way of knowing in history. Written communication, 15(1), 25-68.

McCarthy Young, K., \& Leinhardt, G. (1998b). Wildflowers, sheep and democracy: The role of analogy in the teaching and learning of history. In J. F. Voss, \& M. Carretero (Eds.) Learning and reasoning in history. International review of history education (Vol 2) (pp. 154-156). London: Woburn.

McKeown, M. G., \& Beck, I. L. (1990). The assessment and characterization of young learners' knowledge of a topic in history. American Educational Research Journal, 27(4), 688-726.

O’Reilly, K. (1991). Informal reasoning in high school history. In J. F. Voss, D. N. Perkins, \& J. W. Segal (Eds.) Informal reasoning and education (pp. 363-379). Hillsdale, NJ: Erlbaum.

Perfetti, C. A., Britt, M. A., \& Georgi, M. C. (1995). Text-based learning and reasoning: Studies in history. Hillsdale, NJ: Erlbaum.

Pontecorvo, C., \& Girardet, H. (1993). Arguing and reasoning in understanding historical topics. Cognition and Instruction, 11(3-4), 365-395.

Rivière, A., Nunez, M., Barquero, B., \& Fontela, F. (1998). Influence of intentional and personal factors in recalling historical texts: A developmental perspective. In J. F. Voss, \& M. Carretero (Eds.) Learning and reasoning in history. International review of history education (Vol. 2) (pp. 214-226). London: Woburn.

Roderigo, M. J. (1994). Discussion of chapters 10-12: Promoting narrative literacy and historical literacy. In M. Carretero, \& J. F. Voss (Eds.) Cognitive and instructional processes in history and the social sciences (pp. 309-320). Hillsdale, NJ: Erlbaum.

Rosa, A., Blanco, F., \& Huertas, J. A. (1998). Uses of historical knowledge: An exploration of the construction of professional identity in students of psychology. In J. F. Voss, \& M. Carretero (Eds.) Learning and reasoning in history. International review of history education (Vol. 2) (pp. 61-78). London: Woburn.

Rouet, J. F., Britt, M. A., Mason, R. A., \& Perfetti, C. A. (1996). Using multiple sources of evidence to reason about history. Journal of Educational Psychology, 88(3), 478-493. 
Rouet, J. F., Marron, M. A., Perfetti, C. A., \& Favart, M. (1998). Understanding historical controversies: Students' evaluation and use of documentary evidence. In J. F. Voss, \& M. Carretero (Eds.) Learning and reasoning in history. International review of history education (Vol. 2) (pp. 95-116). London: Woburn.

Schreiber, W., Körber, A., Von Borries, B., Krammer, R., Leutner-Ramme, S., Mebus, S., Schöner, A., \& Ziegler, B. (2006). Historisches Denken. Ein Kompetenz-Strukturmodell.[Historical Thinking. A model of compentences] Ars una, Neuried, Germany.

Seixas, P. (1993). Historical understanding among adolescents in a multicultural setting. Curriculum Inquiry, 23(3), 301-327.

Shemilt, D. (1983). The devil's locomotive. History and Theory, 22(4), 1-18.

Shemilt, D. (2000). The Caliph's coin: The currency of narrative frameworks in history teaching. In P. N. Stearns, P. Seixas, \& S. Wineburg (Eds.) Knowing, teaching, and learning history. National and international perspectives (pp. 83-101). New York: New York University Press.

Spoehr, K. T., \& Spoehr, L. W. (1994). Learning to think historically. Educational Psychologist, 29(2), 71-77.

Stahl, S. A., Hynd, C. R., Britton, B. K., McNish, M. M., \& Bosquet, D. (1996). What happens when students read multiple source documents in history? Reading Research Quarterly, 31(4), 430-456.

Stearns, P. N. (1998). Goals in history teaching. Learning and Reasoning in history. International review of history education (Vol. 2) (pp. 281-293). London: Woburn.

Stein, N., \& Miller, C. (1993). The development of memory and reasoning skills in argumentative contexts: Evaluating, explaining, and generating evidence. In R. Glaser (Ed.) Advances in instructional psychology. Hillsdale, NJ: Erlbaum.

Stow, W., \& Haydn, T. (2000). Issues in the teaching of chronology. In S. Capel, J. Davison, J. Arthur, \& J. Moss (Series Eds.) \& J. Arthur \& R. Philips (Vol. Eds.), Issues in subject teaching series. Issues in history teaching (pp. 83-97). London: Routledge.

Torney-Purta, J. (1994). Dimensions of adolescents' reasoning about political and historical issues: Ontological switches, developmental processes, and situated learning. In M. Carretero, \& J. F. Voss (Eds.) Cognitive and instructional processes in history and the social cciences (pp. 103-122). Hillsdale, NJ: Erlbaum.

Van Boxtel, C. (2002, June). Small group collaboration compared with teacher-guided collaboration in the whole class. Paper presented at the International Society for Cultural Research and Activity Theory (ISCRAT) Congress, Amsterdam, The Netherlands.

Van Boxtel, C., \& Van Drie, J. (2003, August). Collaborative reasoning as a key concept for analyzing classroom discourse. Paper presented at the 10th European Association for Research on Learning and Instruction (EARLI). Conference, Padova, Italy.

Van Boxtel, C., \& Van Drie, J. (2004). Historical reasoning: A comparison of how experts and novices contextualise historical sources. International Journal of Historical Learning, Teaching and Research, 4(2), 89-97. Retrieved from http://www.ex.ac.uk/historyresource/journalstart.htm.

Van Drie, J. (2005). Learning about the past with new technologies. Fostering historical reasoning in computer-supported collaborative learning, Unpublished doctoral dissertation. The Netherlands: Utrecht University.

Van Drie, J., \& Van Boxtel, C. (2003). Developing conceptual understanding through talk and mapping. Teaching History, 110, 27-32.

Van Drie, J., Van Boxtel, C., Jaspers, J., \& Kanselaar, G. (2005). Effects of representational guidance on domain specific reasoning in CSCL. Computers in Human Behavior, 21(4), 575-602.

Van Drie, J., Van Boxtel, C., \& Van der Linden, J. L. (2006). Historical reasoning in a computer-supported collaborative learning environment. In A. M. O’Donnell, C. E. Hmelo, \& G. Erkens (Eds.) Collaborative learning, reasoning and technology (pp. 265-296). Mahwah NJ: Erlbaum.

VanSledright, B. A., \& Frankes, L. (2000). Concept- and strategic-knowledge development in historical study: A comparative exploration in two fourth-grade classrooms. Cognition and Instruction, 18(2), 239-283.

Von Borries, B. (1994). (Re-)constructing history and moral judgment: On relationships between interpretations of the past and perceptions of the present. In M. Carretero, \& J. F. Voss (Eds.) Cognitive and instructional processes in history and the social sciences (pp. 339-355). Hillsdale, NJ: Erlbaum.

Von Borries, B. (1997). Concepts of historical thinking and historical learning in the perspective of German students and teachers. International Journal of Educational Research, 27(3), 211-220.

Voss, J. (Ed.). (1997). Explanation and understanding in learning history [Special issue]. International Journal of Educational Research, 27(3).

Voss, J. F., \& Carretero, M. (Eds.). (1998). Learning and reasoning in history. International review of history education (Vol. 2). London: Woburn. 
Voss, J. F., \& Means, M. L. (1991). Learning to reason via instruction in argumentation. Learning and Instruction, 1, 337-350.

Voss, J. F., Perkins, D. N., \& Segal, J. W. (1991). Preface. In J. F. Voss, D. N. Perkins, \& J. W. Segal (Eds.) Informal reasoning and education (pp. vii-xvii). Hillsdale, NJ: Erlbaum.

Voss, J. F., Wiley, J., \& Kennet, J. (1998). Student perceptions of history and historical concepts. In J. F. Voss, \& M. Carretero (Eds.) Learning and reasoning in history. International review of history education (vol. Vol. 2, (pp. 307-330)). London: Woburn.

Wertsch, J. V. (1991). Voices of the mind: A sociocultural approach to mediated action. Cambridge, MA: Harvard University Press.

Wertsch, J. V., \& Rozin, M. (1998). The Russian Revolution: Official and unofficial accounts. In J. F. Voss, \& M. Carretero (Eds.) Learning and reasoning in history. International review of history education (Vol. 2), (pp. 39-60). London: Woburn.

Wilson, S. M. (2001). Research on history teaching. In V. Richardson (Ed.) Handbook of research on teaching (4th ed.), (pp. 527-544). Washington DC: American Educational Research Association.

Wineburg, S. S. (1991a). Historical problem solving: A study of the cognitive processes used in the evaluation of documentary and pictorial evidence. Journal of Educational Psychology, 83, 73-87.

Wineburg, S. S. (1991b). On the reading of historical texts: Notes on the breach between school and academy. American Educational Research Journal, 28, 495-519.

Wineburg, S. S. (1994). The cognitive representation of historical texts. In G. Leinhardt, I. L. Beck, \& C. Stainton (Eds.) Teaching and learning in history (pp. 85-136). Hillsdale, NJ: Erlbaum.

Wineburg, S. S. (1998). Reading Abraham Lincoln: An expert/expert study in the interpretation of historical texts. Cognitive Science, 22, 319-346.

Wineburg, S. S. (2001). Historical thinking and other unnatural acts. Charting the future of teaching the past. Philadelphia: Temple University Press. 